\title{
Promoting Access to Health Technologies in the Post-pandemic Era: Gavi, Global Fund, Unitaid, and Access to COVID-19 Tools Accelerator (ACT-A) Programs
}

\author{
Sooyeon Song ${ }^{1,2}$, Jongho $\mathrm{Heo}^{3,4, \dagger}$ \\ ${ }^{1}$ Boston University School of Public Health \\ ${ }^{2}$ Partnered Evidence-Based Policy Resource Center, VA Boston Healthcare System \\ ${ }^{3}$ National Assembly Futures Institute \\ ${ }^{4}$ JW LEE Center for Global Medicine, Seoul National University College of Medicine
}

\author{
포스트 코로나 시대 보건의료기술 접근성 제고를 위한 탐색 연구: \\ 세계백신연합(Gavi) 글로벌펀드(Global Fund), 국제의약품구매기구(Unitaid) \\ 및 Access to COVID-19 Tools Accelerator 사업 사례
}

\author{
송수연 ${ }^{1,2}$, 허종호 ${ }^{3,4, \dagger}$ \\ ${ }^{1}$ 보스턴대학교 \\ ${ }^{2}$ 미 보훈부 보스턴 보건의료체계 연구소 \\ 3국회미래연구원 \\ ${ }^{4}$ 서울의대 이종욱글로벌의학센터
}

\begin{abstract}
코로나19 확산은 전 세계 인구, 보건체계, 경제, 사회문화에 전례 없는 영향을 미치고 있으며, 국제사회는 코로나19를 극복하고자 보건의료기술 개발 및 접근성 제고를 위해 연대하고 있다. 본 고는 보건의료기술 접근성을 저해하는 장애 물에 대한 이론적 틀을 기반으로 감염병 다자기구 및 코로나19 보건의료기술 접근성 제고를 위한 ACT-A 사업을 검 토한다. 연구 결과, 첫째, 국제사회는 필요한 기술의 부재를 극복하기 위해 선시장공약, 백신채권, Covax Facility 등을 시행하고 있으며, 둘째, 존재하는 기술이 접근가능하지 않는 장애물을 극복하기 위해 공동조달메커니즘, 의약품특허풀 등을 시행하고 있으며, 셋째, 기술이 수용되지 않는 장애물을 극복하기 위해 인력역량 강화 등을 포함하는 보건체계 강 화를 지원하고 있음을 발견하였다. 이를 바탕으로 실무적·학술적 향후 과제로써 기추진중인 한국 공적개발원조 사업 과 감염병 다자기구 및 ACT-A 사업과의 연계 가능성을 검토하여 더욱 활발하게 협력할 필요가 있다.

Purpose: Global collaboration to accelerate development and equitable access to COVID-19 tests, treatments, and vaccines was launched with the name of the Access to COVID-19 Tools Accelerator (ACT-A), and this initiative owes its expertise to the lessons learned of the global health organizations. To date, the comprehensive mechanisms and potential effects of the initiative remain largely unknown. Methods: This study reviewed the programs of Gavi, the Global Fund, Unitaid, and ACT-A, which mitigating barriers to greater use of health technology with an analytic framework. Results and conclusion: The study findings are as follows. First, programs to alleviate the absence of necessary technology include the International Finance Facility for Immunization and Covax Facility. Second, Pooled Procurement Mechanism and Accelerated Order Mechanism are examples of mitigating the inability to access technology. Third, programs to overcome reluctance to adopt accessible technology include health system strengthening efforts such as the capacity-building health workforces. Further actions of Korea are needed to collaborate with the initiatives to enhance health outcomes.
\end{abstract}

${ }^{\dagger}$ To whom correspondence should be addressed.

E-mail: joheo@nafi.re.kr

Received: 15 October 2021, Revised: 6 November 2021,

Accepted: 10 November 2021
KEYWORDS: Healthcare technology, Health outcome, Multilateral aid, Program design and evaluation, COVID19 pandemic 


\section{Introduction}

코로나바이러스감염증-19(이하 코로나19) 팬데믹(pandemic) 은 전 세계 인구, 보건체계, 경제, 사회문화에 전례 없는 영 향을 미치고 있다(Armitage et al., 2020; Rundle et al., 2020; Ataguba et al., 2020). 검역 및 사회적 거리두기 등 공중보 건 조치가 코로나19 확산 방지에 활용되고 있으나, 코로나 19 팬데믹 종결을 위한 백신·치료제·진단기기를 포함하는 보건의료기술(health technologies) 개발 및 전 세계 보급은 여전히 시급한 문제이다(Shih et al., 2020) 보건의료기술 접 근성은 전통적으로 자원이 제약된 중저소득국을 배경으로 논의되어 왔다. 그러나, 신종감염병인 코로나 19 는 현재 치 료제 및 백신 개발에 필요한 유전자 정보 등 과학지식이 불 완전하고 불확실하기 때문에 중저소득국 뿐 아니라 고소득 국에서도 보건의료기술 접근성에 대한 논의가 활발하게 일 어나고 있다. 이에 최근 들어 정부, 시민사회, 산업계, 학계 를 포함하는 국제사회는 코로나 19 극복을 위한 보건의료기 술 개발 및 접근성 제고를 통해 연대하고 있다.

이러한 연대의 결실로 2020년 4월말 세계보건기구(WHO) 사무총장, 프랑스 대통령, 유럽연합 집행위원회 의장, 빌앤 멀렌다게이츠재단(Bill \& Melinda Gates Foundation)이 공동 주최한 행사에서 코로나19 관련 백신·치료제·진단기기 개발 을 가속화하고 공평한 분배를 보장하기 위해 Access to COVID-19 Tools Accelerator (ACT-A)가 출범하였다(ACT$\mathrm{A}, 2020) . \mathrm{ACT}-\mathrm{A}$ 는 전세계적으로 정부, 과학자, 기업, 시민 사회, 자선가 및 국제보건 단체들이 참여하고 있다. ACT-A 에 참여하는 감염병 다자기구(Multilateral Organizations)로 는 세계백신면역연합(Global Alliance for Vaccines and Immunization, 이하 Gavi), 글로벌펀드(Global Fund to Fight AIDS, Tuberculosis and Malaria, 이하 Global Fund), 국제의 약품구매기구(International Drug Purchasing Facility, 이하 Unitaid) 등이 포함되었다.

그간 보건의료기술의 접근성과 관련한 선행연구는 백신 ·치료제·진단기기 등 개별 제품의 개발 및 효과성 평가, 특 허권과 의약품 접근성에 집중되어 왔다(Shih et al., 2020;
Attaran, 2004). 지속가능개발목표(Sustainable Development Goals, 이하, SDGs) 시대 및 포스트코로나 시대 보건의료기 술 개발 및 접근성 제고를 위하여 ACT-A에 참여하는 다자 기구 및 이들의 사업 내용을 살펴볼 필요가 있다.

이에 본 연구는 보건의료기술의 개발, 재정적 및 지리적 접근성 제고, 기술의 수용과 관련된 다양한 활동을 포괄할 수 있는 Howitt et al. (2012)의 보건의료기술 접근성을 저 해하는 장애물에 대한 이론적 틀을 기반으로 ACT-A에 참 여하는 감염병 다자기구의 정책 및 사업을 검토하였다. 세 부적으로는 (1) 보건의료기술 및 접근성을 저해하는 장애물 및 극복 방안에 대한 이론적 배경을 살펴보고, (2) 이러한 장애물을 극복하기 위한 감염병 분야 다자기구의 사업을 고 찰한다. 또한, (3) 코로나19 하에서 동 감염병 분야 다자기 구가 공동으로 추진 중인 이니셔티브인 ACT-A를 살펴봄으 로써 코로나19 보건의료기술 접근성 제고를 위한 국제사회 노력을 조망하고 (4) 보건의료기술 접근성 제고를 위한 실 무적·학술적 향후 과제를 도출한다.

\section{Materials and Methods}

\section{1. 보건의료기술 접근성의 이론적 배경}

$\mathrm{WHO}$ 는 “보건의료기술”을 “질병의 예방, 진단, 치료를 위 해 사용되거나, 재활 및 서비스가 제공되는 조직 및 체계에 서 사용되는 의료기기, 의약품, 의료적 및 수술적 술기"로 정의한다(WHO, 2001). 해당 정의는 상해 예방을 위한 헬멧 등 건강성과를 개선하기 위한 다양한 기술을 포괄하는 건 강을 위한 기술(technologies for health)의 정의 범위 보다 협 소하나(Howitt et al., 2012), 코로나19 대응을 위한 국제사 회의 노력이 집중되고 있는 주요 보건의료기술인 백신·치 료제·진단기기를 포괄한다는 점에서 본 연구에 적용하였다.

보건의료기술 접근성은 SDGs의 세부목표(targets) 달성과 밀접한 관련이 있다. SDGs에는 보건의료기술의 접근성을 직접 언급하는 2개의 세부목표(SDG 3.8, SDG 3.b)를 포함 하며(Table 1) 각각 양질의 안전하고 효과적이며 적정가격 의 필수 약품 및 백신에 대한 접근성 및 세계무역기구 무

Table 1. SDGs goals and targets related to health technology

\begin{tabular}{|c|l|}
\hline Goal & \multicolumn{1}{c|}{ Targets } \\
\hline \multirow{3}{*}{$\begin{array}{c}\text { Goal 3. Ensure } \\
\text { healthy lives } \\
\text { and promote } \\
\text { well-being for } \\
\text { all at all ages }\end{array}$} & $\begin{array}{l}\text { Target 3.8: Achieve universal health coverage, including financial risk protection, access to quality essential health-care services } \\
\text { and access to safe, effective, quality and affordable essential medicines and vaccines for all }\end{array}$ \\
\cline { 2 - 2 } & $\begin{array}{l}\text { Target 3.b: Support the research and development of vaccines and medicines for the communicable and non-communicable } \\
\text { with the Doha Declaration on the TRIPS Agreement and Public Health, which affirms the right of developing countries to } \\
\text { use to the full the provisions in the Agreement on Trade-Related Aspects of Intellectual Property Rights regarding flexibilities } \\
\text { to protect public health, and, in particular, provide access to medicines for all }\end{array}$ \\
\hline
\end{tabular}


역 관련 지적재산권에 관한 협정(Agreement on Trade-Related Aspects of Intellectual Property Rights, TRIPS)과 공중보건 에 관한 도하선언에 따른 적정가격의 필수 의약품 및 백신 에 대한 접근을 목표로 한다. 세부목표로 직접 보건의료기 술을 언급하지 않지만, 세부목표 달성이 보건의료기술의 접 근성에 영향을 받는 보건 관련 세부목표는 11 개가 있다 (SDG 3.1, SDG 3.2, SDG 3.3, SDG 3.4, SDG 3.5, SDG 3.6, $\mathrm{SDG}$ 3.7, $\mathrm{SDG} 3.9, \mathrm{SDG} 3 . \mathrm{a}, \mathrm{SDG} 3 . \mathrm{c}, \mathrm{SDG} 3 . \mathrm{d})$. 이들은 감 염병, 성생식모자보건, 비감염병 등을 포괄하는 질환별 세 부목표를 제시하고 있으며 보건의료기술은 접근성 및 서비 스 품질 제고, 비용 절감을 통해 해당 세부목표 달성에 기 여하게 된다.

본 논문에서는 활용한 이론적 분석틀은 국제보건 영역에 서 보건의료기술 접근성 관련 다수 문헌의 이론적 기반이 되는 Howitt et al. (2012)의 "Barriers to greater use of technology for global health"이다. 란셋에 실린 Howitt et al. (2012)의 "Technologies for global health" 논문에서 제시한 국제보건 에서 더 활발하게 사용되어야 할 기술의 사용을 저해하는 장애물을 논하는 분석틀을 활용하여 ACT-A에 참여하는 감 염병 다자기구의 ACT-A 사업에 대한 보건의료기술 접근성 을 검토하였다. Howitt et al. (2012)은 이 리뷰논문에서 새 천년개발목표(Millennium Development Goals) 달성을 위해 중저개발국에서 사용가능한 적정기술이 더욱 많이 필요하 다고 주장하였다. 아울러 다양한 보건의료기술과 그 기술이 보건성과에 미친 효과를 검토한 결과, 보건의료기술의 접근 성을 저해하는 세 가지 주요 장애물을 제시하였다. 첫번째 로, 필요한 기술 자체가 부재한 경우, 둘째, 필요한 기술이 존재하지만 재정적 혹은 기타 이유로 접근이 가능하지 않 은 경우, 셋째, 접근가능한 기술이 존재하지만 현장에서 수 용(adopt)되지 않는 경우이다. 보건의료기술 접근성에 관한 선행연구는 이러한 주요 장애물을 극복하기 위한 전략을 제 시한다. 첫째, 필요한 기술의 부재를 극복하기 위한 방안은 해당 기술이 개발될 수 있도록 재정지원을 하는 추진요인 (push factors) 측면의 개입, 해당 기술의 국제적 수요를 산 출하여 산업계의 연구개발을 촉진하는 유인요인(pull factors) 측면의 개입이 있다(Grace and Kyle, 2009). 둘째, 존재하는 기술의 접근가능성을 제고하기 위한 방안은 경제적 및 지 리적 장애물을 제거하는 데 집중하였다. 지적재산권 및 이 를 반영한 가격 책정은 혁신에 대한 가치를 지불한다는 측 면에서 중요하나 보건의료기술의 경제적 접근성을 제한할 수 있으므로, 특허권 면제(WHO, 2006), 잠재시장의 경제적 수준을 반영한 차등가격제(tiered pricing)(Moon et al., 2011), 비교적 저렴한 가격에 보건의료기술을 생산할 수 있는 국 가로의 기술이전 및 제품 생산(Carger, 2018)이 대안으로 논
의되었다. 지리적 접근성을 제고하기 위한 방안으로는 기 존 재하는 상업 네트워크를 활용하는 방안(USAID, 2019)이 있 다. 셋째, 접근가능한 기술일지라도 문화적 저항 및 현장에 서의 관성으로 수용되지 않는 경우, 행동경제학적 기법을 활 용한 대안이 논의되어 왔다(Dupas, 2011).

\section{ACT-A에 참여하는 감염병 다자기구의 개요}

감염병 다자기구는 경제협력개발기구 개발협력위원회 (Organization for Economic Cooperation and Development, Development Assistance Committee(OECD DAC)가 개발원 조 통계 보고의 기준으로 삼는 Creditor Reporting System (CRS) 코드 목록 중 채널모항목(Channel Parent Category) 분 류상, 4만번대에 해당하는 다자기구(정부 회원 자격을 가진 국제기구에 해당) 중 감염병만을 목적으로 하는 기구로 선 정하였다. 이 기준에 의해 Gavi, Global Fund, Unitaid가 선 정되었다. 국제백신개발채권(International Finance Facility for Immunisation, 이하 IFFIm)은 Gavi 연계 매커니즘으로 포 함하였고, 채널모항목 3만번대(공공-민간 파트너십에 해당) 에 해당하는 전염병대비혁신연합(the Coalition for Epidemic Preparedness Innovations, CEPI)는 제외되었다.

ACT-A에 참여하는 감염병 다자기구인 Gavi, The Global Fund, Unitaid는 다양한 이해관계자로 이루어진 파트너십이 국제보건을 주도하기 시작한 2000년대 초에 발족되었다. 이 들은 국제보건이니셔티브(Global Health Initiative)라고 통칭 되기도 하며, 기능적으로 자금 조달·사업비 지급·조정·실행 과정에서의 일부 공통기반을 공유하나, 제도적 측면의 공통 점은 거의 없다(Biesma et al., 2009)(Table 2). 개별국가가 주 도하는 기존의 $\mathrm{UN}$ 기구 거버넌스 모형과 달리 시민사회, 재 단, 산업계, 학계가 기구의 의사결정에 참여하고 있다 (Gostin, 2014). 감염병 다자기구 중 일부는 UN기구 및 다 자개발은행과 함께 다자기구성과 평가네트워크(Multilateral Organization Performance Assessment Network, MOPAN)와 같은 공여국으로 구성된 외부기관에 의해 주기적으로 평가 받는다.

Gavi는 백신예방가능질병(vaccine preventable disease)을 대상 질환으로 하며 백신 접근성 확대를 통해 어린이 등 인 류 건강 보호를 목적으로 2000년 출범했다. 이를 위해 Gavi 는 자체 지원적격국가에서의 백신예방가능질병을 중심으로 아동 백신접종률 제고를 위한 백신 공급 사업(보장성 강화) 을 추진하며, 백신 공급체계 개선 및 관련 보건인력 역량강 화 등의 보건체계강화 사업 역시 지원하고 있다. 최근, 출 생 후 B형간염 1차접종 지원을 결정하기도 했다(Gavi, 2018). 또한, 안정적으로 재원을 조달하고 백신 개발을 유도하기 위 해 국제백신개발채권(IFFIm), 선구매공약(Advance Market 
Table 2. Gavi, Global Fund, and Unitaid overview

\begin{tabular}{|c|c|c|c|c|}
\hline \multirow{2}{*}{\multicolumn{2}{|c|}{ Founded }} & Gavi & Global Fund & Unitaid \\
\hline & Founded & 2000 & 2002 & 2006 \\
\hline \multicolumn{2}{|c|}{ Disease focus } & Vaccine preventable disease & $\begin{array}{l}\text { HIV/AIDS, Tuberculosis, } \\
\text { Malaria }\end{array}$ & $\begin{array}{l}\text { HIV/AIDS, Tuberculosis, Malaria, } \\
\text { Neglected Tropical Diseases } \\
\text { (Chagas disease), Hepatitis C, etc }\end{array}$ \\
\hline \multicolumn{2}{|c|}{ Primary project strategy } & Coverage expansion & Coverage expansion & Technology development and introduction \\
\hline \multicolumn{2}{|c|}{ Investment examples } & $\begin{array}{c}\text { International Finance Facility for } \\
\text { Immunisation (IFFIm) } \\
\text { Advance Market Commitments (AMC) } \\
\text { Matching Fund }\end{array}$ & $\begin{array}{l}\text { Country funding using Country } \\
\text { Coordinating Mechanisms }\end{array}$ & Medicines Patent Pool (MPP) \\
\hline \multirow[b]{2}{*}{ Governance } & $\begin{array}{c}\text { Decision- } \\
\text { making body }\end{array}$ & Board & Board & Executive board \\
\hline & Committee & $\begin{array}{c}\text { Ethics and Governance Committee } \\
\text { Strategy Committee } \\
\text { Audit and Finance Committee }\end{array}$ & $\begin{array}{c}\text { Programme and Policy committee } \\
\text { Governance Committee } \\
\text { Investment Committee } \\
\text { Audit and Finance Committee } \\
\text { Evaluation Advisory Committee }\end{array}$ & $\begin{array}{l}\text { Finance and accountability committee } \\
\text { Policy and strategy committee }\end{array}$ \\
\hline \multicolumn{2}{|c|}{ MOPAN assessment } & $2012,2015-2016$ & $2012,2015-2016$ & - \\
\hline
\end{tabular}

Commitments, $\mathrm{AMC})$, 매칭펀드 등 다양한 재정적 도구를 활 용하고 있다. 출범 이후 2019년까지 190억불을 관련 사업 에 투입(연평균 9.5억불)하였다. 최고의사결정기구는 이사 회로, 이사진은 시행국가(중저소득국), 공여국, 산업계, 시민 사회, 게이츠재단, World Bank, WHO, UNICEF, 개인전문가 를 포함한다. 분과위원회는 프로그램 및 정책 위원회, 거버 넌스 위원회, 투자 위원회, 감사 및 재무 위원회, 평가자문 위원회로 구성되어 있으며, MOPAN 평가는 2012년, 20152016년 주기 총 2회 수검하였고, 2021년 10월 현재까지 추 가 평가는 없었다.

Global Fund는 3대 감염병(HIV/AIDS-결핵·말라리아) 퇴 치를 위한 자금 조달 및 관리를 목적으로 2000년 출범했다. 사업대상국가 수요에 따른 3 대 감염병 예방-진단·치료를 제 공(보장성 강화)하기 위해조달 및 공급망 강화, 데이터 체 계 및 사용 강화, 지역사회 참여 제고, 통합적이고 인간중 심의 보건서비스 촉진, 보건인력 강화 분야의 보건체계 강 화 등을 지원하고 있다. 출범 이후 해당 사업에 2020년 4월 까지 449억불을 투입(연평균 25 억불)하였다. 최고의사결정 기구는 이사회로, 이사진은 지역적 대표성을 고려한 중저소 득국(아프리카, 서태평양지역 등), 공여국, 재단(게이츠재단 등), 민간 부문(머크사(社) 등), 시민사회(지역사회, 고소득국 비정부기구, 중저소득국 비정부기구로 구성) 등을 포함한다. 분과위원회는 윤리 및 거버넌스 위원회, 전략 위원회, 감사 및 재무 위원회, 조정그룹, 기술평가자문그룹, 기술검토패널 로 구성되어 있으며, MOPAN 평가는 2012년, 2015-2016년 주기 총 2회 수검 하였고, 2021년 현재 추가 평가가 진행중
이다.

Unitaid는 HIV/AIDS, 결핵, 말라리아의 3대 감염병 예방 ·진단·치료를 위한 혁신기술 투자를 목적으로 2006년 출범 했다. 출범 당시 HIV/AIDS, 결핵, 말라리아를 주요 대상 질 환으로 하였으나, 최근 샤가스병 등으로 대상 질환을 확대 하고 있다(Unitaid, 2019). Unitaid는 자체적으로 대상 질환 에 대한 보건의료기술 시장을 분석하고, 확인된 기술 격차 를 줄이기 위한 기술개발 사업 공모를 진행하여 선정된 개 별 사업을 통해 혁신기술 개발 및 도입 확대에 기여하고 있 다. 이는 국가 단위로 대상 질환에 대한 보장성 강화 사업 을 수행하는 Gavi 및 Global Fund사업 형태와 구분된다. 특 히, 중저소득국의 치료제 접근성 강화를 위해 자발적 특허 권 공유를 촉진하는 의약품특허풀(Medicines Patent Pool, $\mathrm{MPP}$ )은 Unitaid의 주요 성취 중 하나이다. 출범 이후 2016 년까지 28억불을 투입(연평균 2.5 억불)하였다. 최고의사결 정기구는 집행이사회로, 이사진은 Unitaid 창립이사국 및 주 요 공여국(한국 포함), 아프리카 국가, 시민사회, 게이츠재 단, $\mathrm{WHO}$ 를 포함한다. 분과위원회는 재무 및 책무성 위원 회, 정책 및 전략 위원회, 제안서 검토 위원회로 구성되어 있으며, MOPAN 평가는 수검하지 않았고, 2021년 10월 현 재까지 계획된 평가는 없다.

\section{Results and Discussion}

\section{ACT-A에 참여하는 감염병 다자기구별 보건의료기술 접 근성 제고 사례}




\section{장애물1: 필요한 기술의 부재 문제의 대응책}

감염병 다자기구는 보건의료기술 접근성을 저해하는 장 애물을 극복하기 위해 다양한 정책 및 사업을 운영하고 있 다(Table 3). 첫째, 필요한 기술이 부재한 장애물을 극복하 기 위해, Gavi는 유인요인 측면의 개입, 즉 재원 조달 확대 및 재정 지원을 통해 연구개발을 촉진하고 있다. 선시장공 약(AMC)은 장기간의 백신 구매를 보장함으로써 백신제조 사들이 중저소득국에 적합하고 저렴한 백신을 생산하도록 장려하였고, 이는 2009년 폐렴구균백신 개발에 적용되어 백 신 출시로 이어졌다(Cernuschi et al., 2011). 백신채권(IFFIm) 은 각국 정부의 지원공약을 바탕으로 국제자본시장에서 채 권을 발행하여 백신기금을 모금하되 Gavi가 발행된 채권을 즉각 사용할 수 있는 현금으로 전환하여 공여국의 경제적 부담을 줄이는 동시에 백신 공급 자금 확보에 기여하고 있 다(Gavi, 2020). 매칭펀드는 일부 공여기관이 기업 등 민간 단체가 기부한 금액만큼 추가로 Gavi에 기부하기로 약정하 여 기업 및 재단의 기부를 촉진하는 정책으로, 2011-2020년 간 공여기관을 통해 약 1 억 9,700 만불의 추가 기여가 이루 어졌다. Unitaid는 유인요인 측면의 개입을 위해 대상질환 및 제품(진단기기, 치료제 등)별 기술 현황 분석(market and technology landscape analysis)을 주기적으로 진행하고 결과 를 공개하여 관련 기관의 연구개발을 촉진하고 이러한 분 석 결과에 기반하여 어린이용 다제내성결핵 치료제 개발 사 업 등을 직접 지원한다. 한편, Gavi, Global Fund, Unitaid는 추진요인 개입의 일환으로 공동으로 말라리아 백신(RTS,S/ $\mathrm{AS} 01)$ 시범사업을 지원하는 등 신규 보건의료기술 개발을
위해 협력하였고(글로벌펀드, 2019), 해당 말라리아 백신은 $\mathrm{WHO}$ 에 의해 사용 승인을 받는 성과를 달성했다 $(\mathrm{WHO}$, 2021).

\section{장애물2: 접근 가능하지 않은 기술 문제의 대응책}

존재하는 기술이 접근 가능하지 않는 장애물을 극복하기 위해, 감염병 다자기구는 경제적 장벽을 낮추기 위한 정책 및 사업을 추진하고 있다. Gavi 선구매공약(AMC)은 백신 제조사가 중저소득국 대상 낮은 공급가격을 유지하게 함으 로써 백신의 경제적 접근성을 향상시키고 백신 생산능력 확 대를 통한 백신 가용성 확대에 기여하였다(Gavi, 2020). 그 러나, $\mathrm{AMC}$ 는 투입 사업비 대비 달성한 백신 가격 인하 수 준이 충분한지, $\mathrm{AMC}$ 를 통한 백신 가격 인하보다 $\mathrm{UNICEF}$ 입찰을 통해 더 저렴하게 백신을 조달할 수 있는 것은 아 닌지 우려도 있었다(Wilson, 2010). Global Fund는 의약품 등 보건제품의 전략적 구입을 위해 공동조달메커니즘(Pooled Procurement Mechanism, PPM)을 사용한다. PPM은 글로벌 펀드 지원 사업들이 사용하는 보건제품별 총량을 산정하여 사업 시행자를 대신하여 제조업체와 가격 및 조달 조건을 협상하여 규모의 경제를 실현한다. Global Fund는 동 메커 니즘을 통해 2019년 1억 7,400만불을 절감했다고 밝히고 있 다(Global Fund, 2020). 최근 온라인조달플랫폼(Wambo.org) 을 통해 $\mathrm{PPM}$ 협상 조건 및 가격을 공개하여 시장 가시성 을 제고하고 있다. Global Fund가 의약품 제조업체에의 공 동부담금(co-payment)을 지불하여 의약품 수입업체의 부담 을 낮추는 민간부문 공동지불 메커니즘(private sector co-

Table 3. Health technology program examples of Gavi, Global Fund, and Unitaid

\begin{tabular}{|c|c|c|c|c|}
\hline & & Gavi & Global Fund & Unitaid \\
\hline \multirow{3}{*}{$\begin{array}{c}\text { Barrier } 1 . \\
\text { Necessary technology } \\
\text { does not exist }\end{array}$} & $\begin{array}{l}\text { Funding issues - } \\
\text { Push factors }\end{array}$ & $\begin{array}{l}\text { Project investment (RTS,S/AS01 } \\
\text { malaria vaccine trial, etc) }\end{array}$ & $\begin{array}{c}\text { Project investment (RTS,S/AS01 } \\
\text { malaria vaccine trial, etc) }\end{array}$ & $\begin{array}{l}\text { Project investment }(\mathrm{RTS}, \mathrm{S} / \mathrm{AS} 01 \\
\text { malaria vaccine trial, R\&D etc) }\end{array}$ \\
\hline & $\begin{array}{l}\text { Funding issues - } \\
\text { Pull factors }\end{array}$ & $\begin{array}{c}\text { AMC } \\
\text { IFFIm } \\
\text { Matching fund }\end{array}$ & - & $\begin{array}{c}\text { Market and technology landscape } \\
\text { analysis }\end{array}$ \\
\hline & Scientific issues & - & - & - \\
\hline $\begin{array}{c}\text { Barrier } 2 . \\
\text { Technology exists, } \\
\text { but is not accessible }\end{array}$ & $\begin{array}{c}\text { Cost } \\
\text { Challenges of } \\
\text { distribution } \\
\text { Inadequate human } \\
\text { resources } \\
\text { Unreliable energy } \\
\text { supply }\end{array}$ & $\begin{array}{l}\text { AMC } \\
\text { Project investment (building } \\
\text { cold chain infrastructure, etc) }\end{array}$ & $\begin{array}{c}\text { Pooled Procurement Mechanism } \\
\text { (PPM) } \\
\text { Wambo.org } \\
\text { Private sector co-payment } \\
\text { mechanism }\end{array}$ & $\begin{array}{c}\text { MPP } \\
\text { Project investment } \\
\text { (technology transfer, etc) }\end{array}$ \\
\hline $\begin{array}{c}\text { Barrier } 3 . \\
\text { Accessible technology } \\
\text { is not adopted }\end{array}$ & $\begin{array}{l}\text { Cultural resistance } \\
\text { Human Inertia }\end{array}$ & $\begin{array}{l}\text { Project investment (workforce } \\
\text { capacity building, etc) }\end{array}$ & $\begin{array}{l}\text { Project investment (workforce } \\
\text { capacity building, etc) }\end{array}$ & $\begin{array}{l}\text { Project investment (workforce } \\
\text { capacity building, etc) }\end{array}$ \\
\hline
\end{tabular}


payment mechanism)을 활용하기도 한다(Global Fund, 2019). Unitaid는 의약품특허풀(MPP)을 통해 자발적 의약품 생산 기술 및 특허권 공유를 유도하여 복제약 생산을 촉진하며, 현재 18 개 의약품 생산권을 보유하고 있다(Unitaid, 2020). 그 밖에 결핵 진단기기 생산 기술 이전 등을 통해 저렴한 제품 생산을 지원하고 있다.

\section{장애물3: 수용되지 않는 기술 문제 대응책}

셋째, 기술이 수용되지 않는 장애물을 극복하기 위해, 감 염병 다자기구는 서비스 접근성을 강화하고 혁신기술 개발 ·도입 확대를 위한 개별 사업을 지원하는 동시에, 신규 보 건의료기술을 도입하는 개별 사업 내 지역사회와 보건의료 인력 재교육, 참여 강화 등 사업 요소를 강화함으로써 보건 의료기술 수용을 촉진한다.

\section{2. 코로나19 상황에서 보건의료기술 접근성 제고를 위한 $\mathrm{ACT}-\mathrm{A}$ 의 활동}

ACT-A는 코로나19 관련 백신·치료제·진단기기 개발을 가 속화하고 공평한 분배를 보장하기 위해 2020년 4월 한시적 이니셔티브로 출범했다. 2021년 2월 142개국에 2억만 도즈 백신 공급을 시작으로, 현재 COVID-19 사업비 조달, 백신 기부 및 조달 지원, 진단기기 배포 확대 등을 지원하고 있 다(WHO, 2021). 하위 분과로 백신, 치료제, 진단기기, 보건 체계 분과를 포함한다. 보건의료기술 분과별로 접근성 제고 를 위한 정책 및 사업 사례를 주요 장애물별로 분류한 결 과는 Table 4와 같다. 개별 기술 개발 및 보급을 일차목적 으로 하지 않는 보건체계 분과는 표에서 제외하였다.

백신 분과는 2021년 말까지 백신 개발, 생산능력 제고, 공 급을 통해 전 세계에 20 억 도즈를 공급하는 것을 목표로 하 며, 주관기관으로 Gavi와 CEPI가 활동한다. Gavi는 백신 조 달 및 대량 공급을 위해 COVID-19 Vaccine Global Access (Covax) Facility를 운영하고 있다. 이를 통해 백신제조사와 중저소득국 및 고소득국에 보급할 백신의 적정 기준가격을
협의함으로써 백신의 경제적 접근성 제고하고 있다(장애물 2). 세부적으로 공적개발원조를 통해 중저소득국 백신 공급 재원을 확보하기 위한 Covax 선구매공약(AMC) 및 고소득 국이 자부담금을 지불하고 자국에 백신을 공급하는 Selffinancing Participants라는 총 2개의 재정적으로 분리된 메커 니즘으로 구성된다. Covax Facility는 2020년 10월 기준 184 개국이 참여하고 있다(WHO, 2020). CEPI는 백신 개발과 생 산을 촉진하기 위해 10 개의 백신후보물질을 직접 지원하고 있으며(장애물1), 2021년 10월까지 144개국에 3억만 도즈를 공급하고 있다(Gavi, 2021)

치료제 분과는 2021년 중반까지 2억 4,500만개 COVID19 치료제를 개발·제조·공급하는 것을 목표로 하며, Unitaid 와 웰컴트러스트(Wellcome Trust)가 주관기관이다. Unitaid 는 덱사메타손 효과성 평가 등 치료제 개발(장애물1), 중저 소득국 인증 역량 강화를 지원한다. 웰컴트러스트는 코로나 19 치료제 개발 임상시험 지원(장애물1), 코로나19 치료제 연구비 지원을 위한 민간 자금 모금(장애물1)을 진행한다 (Wellcome Trust, 2020). 진단기기 분과는 2021년 중반까지 중저소득국에 2-3개의 고품질의 진단키트 도입 등을 목표 로 하며, 주관기관으로 혁신진단재단(The Foundation for Innovative New Diagnostics, FIND)과 Global Fund가 활동한 다. $\mathrm{FIND}$ 는 개별 국가의 의사결정 지원을 위해 $\mathrm{WHO}$ 와 협 력하여 분자·면역진단에 대한 독립평가 수행, 코로나19 진 단기기에 대한 파이프라인 및 성능 데이터를 수집·공개한 다(장애물1)(FIND, 2020), 글로벌펀드는 코로나19 진단기기 구입 및 조달을 촉진하기 위한 신속구매메커니즘(Accelerated Order Mechanism, AOM) 및 개발된 진단기기의 단가 절감 등을 목표로 하는 전략적 민간협력 워킹그룹을 운영한다 (장애물2). 보건체계 분과는 백신·치료제·진단기기 활용을 촉진하기 위한 인력 역량강화 등의 보건체계 강화를 목표 로 하며, 주관기관으로 Global Fund와 세계은행(World Bank)이 활동한다.

셋째, 기술이 수용되지 않는 장애물을 극복하기 위해, 백

Table 4. Health technology program examples of Access to COVID-19 Tools Accerlerator (ACT-A) by pillars

\begin{tabular}{|c|c|c|c|}
\hline Pillars & Vaccines & Therapeutics & Diagnostics \\
\hline $\begin{array}{c}\text { Becessary technology } \\
\text { does not exist }\end{array}$ & $\begin{array}{c}\text { COVAX Facility } \\
\text { Investment of Covid-19 } \\
\text { Vaccine R\&D }\end{array}$ & $\begin{array}{c}\text { Project investment (Therapeutics R\&D) } \\
\text { Rapid evidence assessment of candidates }\end{array}$ & $\begin{array}{c}\text { R\&D of tests \& digital tools } \\
\text { (independent evaluations of molecular } \\
\text { tests and immunoassays, etc) }\end{array}$ \\
\hline $\begin{array}{c}\text { Barrier 2. } \\
\text { Technology exists, } \\
\text { but is not accessible }\end{array}$ & Covax Facility & $\begin{array}{c}\text { Market preparedness, facilitating market } \\
\text { entry and supply at scale }\end{array}$ & $\begin{array}{c}\text { Accelerated Order Mechanism (AOM) } \\
\text { Supply, pooled procurement \& equitable } \\
\text { distribution of tests }\end{array}$ \\
\hline $\begin{array}{c}\text { Barrier 3. } \\
\text { Accessible technology is } \\
\text { not adopted }\end{array}$ & $\begin{array}{c}\text { Project investment (Adequate } \\
\text { deployment in all countries) }\end{array}$ & $\begin{array}{c}\text { Project investment (Adequate } \\
\text { deployment in all countries) }\end{array}$ & $\begin{array}{c}\text { Project investment (Adequate } \\
\text { deployment in all countries) }\end{array}$ \\
\hline
\end{tabular}


Table 5. Examples of Korean ODA programs to improve accessibility and affordability

\begin{tabular}{|c|c|}
\hline & Examples of Korean ODA programs \\
\hline $\begin{array}{c}\text { Becessary technology does not exist } \\
\text { Barrier 2. }\end{array}$ & $\begin{array}{c}\text { Global Disease Eradication Fund program (Core contributions to multilateral organizations) } \\
\text { KOICA Creative Technology Solution (CTS) program } \\
\text { Research Investment for Global Health Technology (RIGHT) Fund }\end{array}$ \\
$\begin{array}{c}\text { Global Disease Eradication Fund program } \\
\text { Technology exists, but is not accessible }\end{array}$ & $\begin{array}{c}\text { KOICA CTS program } \\
\text { RIGHT Fund }\end{array}$ \\
\hline $\begin{array}{c}\text { Barrier 3. } \\
\text { Contributions to multilateral organizations and project-type intervention) }\end{array}$ \\
\hline
\end{tabular}

신·치료제·진단기기·보건체계 분과는 사업 내 세부요소로 신규 보건의료기술 도입을 촉진하기 위한 보건인력 역량 강 화를 포함하는 등 보건의료체계 강화를 지원함으로써 개발 된 보건의료기술 수용을 촉진한다.

앞서 살펴본 감염병 다자기구 및 코로나19 보건의료기술 접근성 제고를 위한 ACT-A 정책 및 사업 사례를 바탕으로 첫째, 보건의료기술 접근성 강화를 위해 기추진중인 한국 공 적개발원조 사업과 감염병 다자기구 및 ACT-A 사업과의 연 계 가능성을 검토해 볼 수 있다. 보건의료기술 접근성 제고 를 일차 목적으로 하는 한국 공적개발원조 사업은 국제질 병퇴치기금, 한국국제협력단(Korea International Cooperation Agency, KOICA) 혁신적기술프로그램(Creative Technology Solution, CTS), 글로벌헬스기술연구기금(Research Investment for Global Health Technology Fund, RIGHT Fund)를 포함한 다(Table 5). 국제질병퇴치기금은 Gavi, 글로벌펀드, Unitaid, $\mathrm{CEPI}$ 를 지원하며 Covax $\mathrm{AMC}$ 설계 등 감염병 다자기구의 보건의료기술 접근성 제고 논의에 기여하는 한편(KOICA, 2020; Gavi, 2020; 글로벌펀드, 2020; Unitaid, 2020), 연구개 발 비용 및 전문성을 민간 및 공공이 분담함으로써 보건의 료기술 개발을 촉진하는 추진요인 측면의 대안인 제품개발 파트너십(Product Development Partnership)(Howitt et al., 2012)과의 협업 역시 추진 중이다(TB Alliance, 2020). 한국 국제협력단의 혁신적기술프로그램(KOICA CTS)는 자원이 제약된 환경에서 활용 가능한 기술 개발 사업을 지원(KOICA, 2020)하는 또 다른 추진요인 측면의 개입이다. 글로벌헬스 기술연구기금(RIGHT Fund)는 백신·치료제·진단·디지털 헬 스 분야에서 저소득국가의 공중보건 수요를 충족하기 위한 보건의료기술 개발을 지원하며, 라이선스·가격책정·공급을 포괄하는 제품 접근성 강화 정책을 추진 중이다(RIGHT Fund, 2020). 세 프로그램의 공개된 사업 중 문화적 저항 및 관성 등 특정 제품의 수용(adopt) 자체를 일차인 목표로 하 는 사업을 확인할 수 없다는 점에서, 세 프로그램은 주로 필 요한 기술이 부재하거나 존재하는 기술이 접근가능하지 않
는 장애물 극복을 우선적인 목표로 하는 것으로 보인다. 보 건의료기술 개발 자체 만으로는 보건성과 개선을 달성하기 에 불충분하고 효과적인 전달체계, 확대보급을 위한 재정수 단, 현장에서의 수용 등과 결합되어야 한다는 점에서(Howitt et al., 2012), 감염병 다자기구 사업 혹은 국내 유관 공적개 발원조 사업과의 연계를 검토해 볼 수 있다.

둘째, 학술적으로, 보건의료기술 개발·기술의 재정적 혹은 기타 제약 극복·현장에서의 수용을 촉진하는 국제사회의 정 책 도구를 보다 체계적으로 정리하고 보건성과에 미친 영 향을 평가할 필요가 있다. 이 과정에서, 유사한 원리에 기 반하여 설계·운영 중인 정책 도구일지라도 세부 요소에서 의 차이가 상이한 보건 성과를 산출할 수 있으므로 주요 요 소를 표준화하는 노력이 도움이 될 수 있다. 가령, 폐렴구 균백신 선구매공약(AMC)과 코로나19 백신 선구매공약 (AMC)은 유사한 원리를 기반으로 기획되었으나 비용부담 유무, 대상 국가 등 설계의 세부요소에서 다소 차이가 있으 며 이 차이는 상이한 보건성과로 이어질 수 있다. 이러한 분 석을 바탕으로 각 정책 도구가 보건성과에 미친 영향 평가 가 필요하다. 특히 본 연구에서 분석한 정책 중 다수가 재 원조달(mobilizing), 공급 확대 및 위험 분산(pooling), 구매 (purchasing) 측면의 경제적 도구를 주된 원리로 활용하고 있 다는 점에서 보건경제학적 접근이 도움이 될 수 있으며, 개 별 기술 평가 지원 및 추가적 연구개발이 필요한 보건 수 요를 규명하기 위한 접근도 필요하다.

본 연구의 한계점은 다음과 같다. 첫째, 본 연구는 감염 병 다자기구의 포괄적인ACT-A 사업을 연구 대상으로 했다. 따라서, 세부적인 하부 사업들에 있어서는 여러 장애물들이 중복되어 나타날 수도 있다. 하지만 보건의료기술 접근성 관 련 다수 문헌의 이론적 기반이 되는 Howitt et al. (2012)의 분석틀을 사용하여 ACT-A 사업에 대한 이해와 향후 방향 설정을 돕고자 하였다. 둘째, 감염병 다자기구 및 ACT-A 홈 페이지 내 공개자료를 자료원으로 했기 때문에 일반에 공 개되지 않은 사업이 추가로 존재할 수 있고 전체 사업을 포 
괄하지 않을 수 있다. 하지만 본 연구는 Covax Facility 등 감염병 다자기구의 보건의료기술 접근성 관련 연구자들의 이해를 돕고 향후 세부사업 관련 연구의 기반이 될 수 있 는 주요 사업을 정리했다는 점에서 의미가 있다.

\section{Conclusion}

본 연구는 Howitt et al. (2012)의 보건의료기술 접근성을 저해하는 장애물에 대한 이론적 틀을 기반으로 감염병 다 자기구 및 코로나19 보건의료기술 접근성 제고를 위한 ACT-A 정책 및 사업을 검토했다. 연구 결과, 첫째, 필요한 기술의 부재를 극복하기 위해 감염병 다자기구 및 ACT-A 는 선시장공약(AMC), 백신채권(IFFIm), 매칭펀드, Loan Buydown Facility, 기술 현황 분석, Covax Facility, 백신 후 보물질 개발 지원, 임상시험 지원, 진단기기 독립평가 등을 시행하고 있다. 둘째, 존재하는 기술이 접근가능하지 않는 장애물을 극복하기 위해 감염병 다자기구 및 ACT-A는 선 시장공약(AMC), 공동조달메커니즘, 온라인조달플랫폼, 민 간부문 공동지불 메커니즘, 의약품특허풀(MPP), Covax Facility, 신속구매메커니즘(AOM) 등을 시행하고 있다. 셋째, 기술이 수용되지 않는 장애물을 극복하기 위해 감염병 다 자기구 및 ACT-A는 인력역량강화 등을 포함하는 보건체계 강화 활동을 지원하고 있다.

본 연구는 보건의료기술 접근성 제고를 위한 최근 국제 사회의 정책 및 사업을 포괄적으로 탐색한 첫 연구라는 점 에서 의미가 있다. 본 연구결과를 바탕으로 한 실무적-학술 적 향후 과제를 다음과 제시하였다. 첫째, 실무적으로, 보건 의료기술 접근성 강화를 위해 기추진중인 한국 공적개발원 조 사업과 감염병 다자기구 및 ACT-A 사업과의 연계 가능 성을 검토하고, 둘째, 학술적으로, 보건의료기술 개발, 기술 의 재정적 혹은 기타 제약 극복, 현장에서의 수용을 촉진하 는 국제사회의 정책 도구를 보다 체계적으로 정리하고 보 건성과에 미친 영향을 평가할 필요가 있다.

\section{References}

ACT-A. (n.d.). The Access to COVID-19 Tools (ACT) Accelerator. Retrieved October 25, 2020, Available from https:// www.who.int/initiatives/act-accelerator

Armitage, R., \& Nellums, L. B. (2020). COVID-19 and the consequences of isolating the elderly. The Lancet Public Health, $5(5), \mathrm{e} 256$.

Ataguba, J. E. (2020). COVID-19 pandemic, a war to be won: understanding its economic implications for Africa.
Attaran, A. (2004). How do patents and economic policies affect access to essential medicines in developing countries?. Health Affairs, 23(3), 155-166.

Biesma, R. G., Brugha, R., Harmer, A., Walsh, A., Spicer, N., \& Walt, G. (2009). The effects of global health initiatives on country health systems: a review of the evidence from HIV/ AIDS control. Health policy and planning, 24(4), 239-252.

Cernuschi, T., Furrer, E., Schwalbe, N., Jones, A., Berndt, E. R., \& McAdams, S. (2011). Advance market commitment for pneumococcal vaccines: putting theory into practice. Bulletin of the World Health Organization, 89, 913-918.

Crager, S. E. (2018). Improving global access to new vaccines: intellectual property, technology transfer, and regulatory pathways. American journal of public health, 108(S6), S414-S420.

Dupas, P. (2011). Health behavior in developing countries. Annu. Rev. Econ., 3(1), 425-449.

FIND. (n.d.) COVID-19 Diagnostics \& testing. Retrieved October 25, 2020, Available from https://www.finddx.org/covid-19/

Gavi. (2018). Gavi Board starts framing Alliance's approach to 2021-2025 period. Retrieved October 25, 2020, Available from https://www.gavi.org/gavi-board-starts-framing-alliance-s-approach-to-2021-2025-period

Gavi. (2019). 2019 Pneumococcal AMC Annual Report. Geneva: Gavi. Retrieved October 25, 2020, Available from https:// www.gavi.org/sites/default/files/document/2020/2019-Pneumococcal-AMC-Annual-Report.pdf

Gavi. (n.d.). Gavi Alliance. Retrieved October 25, 2020, Available from http://www.rightfund.org

Global Fund. (2019). Partnership Welcomes Launch of First Malaria Vaccine Pilot. Retrieved October 25, 2020, Available from https://www.theglobalfund.org/en/news/2019-04-23partnership-welcomes-launch-of-first-malaria-vaccine-pilot/

Global Fund. (2016). Technical Brief-Malaria Case Management in the Private Sector.

Global Fund. (n.d.). Government Donors: Republic of Korea. Retrieved October 25, 2020, Available from https://www.theglobalfund.org/en/government/profiles/korea-republic/

Global Fund. (n.d.). Sourcing \& Management of Health products. Retrieved October 25, 2020, Available from https://www.theglobalfund.org/en/sourcing-management/procurement-tools/

Global Fund. (n.d.). the Global Fund. Retrieved October 25, 2020, Available from https://www.theglobalfund.org/en/

Gostin, L. O. (2014). Global health law. Harvard University Press, pp. 129-174.

Grace, C., \& Kyle, M. (2009). Comparative Advantages of Push and Pull Incentives for Technology Development: Lessons for Neglected Diseases. Global Forum Update on Research for 
Health.

Howitt, P., Darzi, A., Yang, G. Z., Ashrafian, H., Atun, R., Barlow, J., \& Wilson, E. (2012). Technologies for global health. The Lancet, 380(9840), 507-535.

Hsin-I Shih, Chi-Jung Wu, Yi-Fang Tu, \& Chia-Yu Chi. (2020). Fighting COVID-19: A quick review of diagnoses, therapies, and vaccines. Biomedical Journal, 43(4), 341-354.

KOICA. (n.d.). KOICA Creative Technology Solution Programs. Retrieved October 25, 2020, from http://www.koica.go.kr/koica_en/3446/subview.do

Moon, S., Jambert, E., Childs, M., \& von Schoen-Angerer, T. (2011). A win-win solution?: A critical analysis of tiered pricing to improve access to medicines in developing countries. Globalization and Health, 7(1), 1-11.

MOPAN. (n.d.). Assessment Packages. Retrieved October 25, 2020, Available from http://www.mopanonline.org/assessments/

OECD. (n.d.). DAC and CRS code lists. Retrieved October 24, 2020, from http://www.oecd.org/dac/financing-sustainabledevelopment/development-finance-standards/annex $2 . \mathrm{htm}$

RIGHT Fund. (n.d.). Research Investment for Global Health Technology Fund. Retrieved October 25, 2020, from http:// www.rightfund.org

Rundle, A. G., Park, Y., Herbstman, J. B., Kinsey, E. W., \& Wang, Y. C. (2020). COVID-19 related school closings and risk of weight gain among children. Obesity, 28(6), 1008-1009.

TB Alliance. (2020). TB Alliance with the Support of the Republic of Korea Announce Initiative to Broaden Adoption and Scale Up of New Treatments for Drug-Resistant Tuberculosis. Retrieved October 25, 2020, from https://www.tballiance.org.za/news/lift-tb-press-release-english

U.S. Agency for International Development. (2019). Project last mile. Retrieved October 23, 2020, Available from https:// www.usaid.gov/cii/project-last-mile

Unitaid. (2019). Unitaid seeks to support new approaches to tackle Chagas disease. Retrieved October 25, 2020, Available from https:/unitaid.org/news-blog/unitaid-seeks-to-support-newapproaches-to-tackle-chagas-disease/\#en

Unitaid. (n.d.). Unitaid Medicine Patent Pool. Retrieved October 25, 2020, Available from https://unitaid.org/project/medicines-patent-pool/\#en

Unitaid. (n.d.). Unitaid. Retrieved October 25, 2020, Available from https://unitaid.org/\#en

Wellcome Trust. (n.d.). Covid-19 treatments: latest on research. Retrieved October 25, 2020, Available from https://wellcome.org/what-we-do/our-work/coronavirus-covid-19/treatments

World Health Organization. (2001). Health care technology management: Eastern Mediterranean Regional strategy for appropriate health care technology.

WHO. (n.d.). Public health innovation and intellectual property rights: report of the Commission on Intellectual Property Rights, Innovation and Public Health. Geneva: WHO. Retrieved October 25, 2020, Available from http://www.who.int/intellectualproperty/en/

WHO. (2020). 172 countries and multiple candidate vaccines engaged in COVID-19 vaccine Global Access Facility. Retrieved October 25, 2020, Available from https://www.who.int/news/ item/24-08-2020-172-countries-and-multiple-candidate-vaccines-engaged-in-covid-19-vaccine-global-access-facility

Wilson, P. (2010). Giving developing countries the best shot: An overview of vaccine access and R\&D. Campaign for Access to Essential Medicines, 16. 